\title{
The Representation of Space and Trauma Narration in In the Country of Last Things
}

\author{
Ying Huang \\ Zhejiang Yuexiu University, Shaoxing, China \\ Email: 20131050@zyufl.edu.cn
}

How to cite this paper: Huang, Y. (2021) The Representation of Space and Trauma Narration in In the Country of Last Things. Open Access Library Journal, 8: e1717. https://doi.org/10.4236/oalib.1107717

Received: July 1, 2021

Accepted: August 13, 2021

Published: August 16, 2021

Copyright $\odot 2021$ by author(s) and Open Access Library Inc.

This work is licensed under the Creative Commons Attribution International License (CC BY 4.0).

http://creativecommons.org/licenses/by/4.0/ (c) (i) Open Access

\begin{abstract}
This paper presents a critical analysis of the typical dystopian novel In the Country of Last Things by employing both the spatial and trauma narration theories. Through the epistolary narrative form of the protagonist Anna, Paul Auster constructs a gloomy and anti-utopian world. The author criticizes and satirizes the ugly side of modern society with the help of postmodern writing techniques and trauma narration. This thesis further exposes the power and discourse behind space reflected in the novel to achieve a deeper understanding of the harsh critique on social reality.
\end{abstract}

\section{Subject Areas}

Literature

\section{Keywords}

Spatial Theory, Trauma Narration, In the Country of Last Things

\section{Introduction}

The contemporary American Jewish writer Paul Auster wrote and published the novel In the Country of Last Things in 1987. The novel adopts a unique epistolary form from the protagonist Anna's perspective in a nearly isolated gloomy city. The whole novel is a long letter with the fragmental sentences from Anna's first point of view. Her brother William was lost in the epidemic, so she went to the infernal city to find him. Everything including memory could only exist temporarily in this city. Thus, Anna had no choice but to write letters to record herself to avoid the aphasia. Finally, she completed her gradual self-improvement after a series of unfortunate experiences.

Paul Auster employed many metaphors and vivid descriptions to create a pa- 
norama of people's struggles in this imagined city. Given that the relevant background description of the novel is highly realistic and critical, it is praised by critics as "a contemporary masterpiece of describing hell" [1]. Since publication, critics at home and abroad have paid close attention to it. Mark Brown thinks that the main themes of this novel can be summarized as "urban space, language, refuge and identity" [2]. Katharine Washburn points that this is "not a future dystopia, but a hellish scene of the present world, where ethics, spirit and culture are in a mess" [3].

In fact, Auster uses postmodern collage and hybridity, thus presenting the city that integrates human beings' agonies and suffering in different historical time, for instance, the European ghetto before the end of the 18th Century, the concentration camp by the Nazis during World War II, and the slums coexisting with modern prosperous cities. These landscape descriptions create a surreal effect of defamiliarization and terror, which makes readers feel shocked and inspired. As an anti-utopian novel, In the Country of Last Things vividly reproduces all kinds of sufferings in the human being's collective memory from ancient to the present, which has already been discussed and studied from home and abroad. On the other hand, the novel also contains many depictions of the spatial metaphor to reveal the normality of individual life especially women's trauma and dilemma in society. Therefore, through the depiction of three layers of space people survive in, the novel highlights the political connotation of power and discourse behind the reality. Given the similar descriptions of the epidemic and chaos, we can also find some new light from it especially after experiencing the similar lockdown in COVID-19.

The American geographer Edward W. Soja divided the space of human existence into three categories: "material space, social space and spiritual space. In literary works, material space generally refers to people's actual living space, which is often presented in the form of region, scene and architecture. Social space refers to the group space, including a series of social practical activities such as the mode of production, social relations of production and human subjective behavior. The spiritual space mainly shows consciousness space, including people's experience, subject construction, culture, language" [4]. The three different kinds of levels of space not only interact and produce each other, but also have a subtle impact on the identity, life, psychology and other aspects of space residents.

Therefore, the following analysis mainly focuses on Anna's traumatic writing in different spatial levels, with the view to exploring Anna's predicament in the suppressed and hopeless city.

\section{Visible Space of Sufferings and Struggling}

Generally speaking, the city is a space full of orders to meet the needs of human security and survival. However, Auster set up a closed, isolated and chaotic city in this novel. In this city, you are only allowed to enter but not to leave. There is 
a smell of death everywhere. Everything is fleeting, including weather and even memory. Hunger is an eternal problem that no one can avoid. Compared with survival, death is what people in the city actively strive for. Even babies refuse to be born, and the haze of death always covers the whole city. All of these features made it a real doomed city.

Even so, the protagonist Anna still went there without any hesitation to find her missing brother William. He was sent there as an interviewer to give reports every week on people's living situation in the city. However, they were disconnected after a few weeks. It was said that he was missing after the outbreak of the epidemic a year ago. When she was looking for him according to the address, the office was replaced by ruins. What's worse, the government locked down and burned the whole region completely. It seems impossible to find William but Anna still insisted with her search. When most of the people in the city were forced to escape and die, Anna struggled to find him and survived in the city. Even though she was always hungry, she still tried her best to help other people in danger. After the shock of losing her lover and child, she even succeeded in overcoming despair and devoting herself actively to helping others.

According to the arrangement of urban region, the eschatological city in the novel is a typical isolated and self-enclosed city. It is located on an unnamed island with a crematorium on the edge. The coastal area is separated by a huge sea wall, and the police strictly defend it. People are not allowed to leave the city at will. In the West and South of the nameless Island, there are forced labor camps. Beyond the western labor camp, there is a boundless desert, from which no one can escape [5]. This isolated visible space also reflects the alienation and exile of the residents.

In terms of the epidemic, the prosperous city life was deprived and the citizens fell into a vacuum, and the government established a blockade seawall to isolate the whole area from the outside world. The pace of life of the residents has been suspended, and they have begun to reflect on the nature of their past life and work. Similar with our experience during the COVID-19, the scarce resources are not masks, but trolleys in the novel, because people use them to carry all the goods and materials stolen or picked up. Collecting wastes is a job that most people have to do, because there are few jobs left in the traditional sense. Besides, you also need to obtain a legal certificate from the government department before you are qualified. People rely on their humble income to buy a cart that can help them pick up waste more efficiently. After having a cart, in order to prevent thieves from stealing, they have to buy a special lock to tie themselves to the cart..., thus, forming an infinite labor cycle. The problem is the harder you work, the weaker you will be. The weaker the body is, the harder you work [5]. The nameless island here also symbolizes the insignificant space of the residents trapped in the city. In the small corner behind the modern urban high-rise buildings or isolated in the edge of the sparsely populated town, although they really exist in the geographical location, they are rare or even nowhere to be 
found. Due to the division of space, they can only survive on the edge. Even if the prosperous metropolis is close at hand, they are also fully developed and isolated from civilization, just like an island in the vast sea, abandoned outside civilization.

At the same time, in the visible space of the eschatological city, scenes with black themes also appear frequently, such as police, desert, forced labor camp and a crematorium, which create an atmosphere of extreme violence and doomed death. It's also the vivid representation and exaggeration of the social reality when we are facing the disastrous epidemic. The black side of humanity is revealed when we are facing the existential threats. Anna failed to escape for the first time. After that, she wrote to her unknown middle-class friend, lamenting that nobody knew about her situation because they were far away [5]. Her failure and loneliness also symbolize the strong concealment of isolated space and the corresponding cultural blindness.

The desolation from the material world to the spiritual world also indicates the collapse of human spiritual civilization.

\section{Self-Salvation of Traumatic Narration}

\subsection{Anna's Traumatic Narration}

In the field of literary criticism, Cathy Caruth firstly explains that trauma is often reflected in the delayed, repetitive and uncontrollable reactions when people face the catastrophic events. It often shows an individual's psychological shock or agony [6].

In fact, this novel is in the epistolary narration from Anna's point of view. Being trapped in death and terror every day in the city, Anna decided to write down her experiences and feelings in her letter. She said that this city will "take away things bit by bit" [5] and no one knows "the exact information of life in the city" [5]. Her writing is fragmental and without concrete or logical meaning. The whole novel is written to her unknown friend "you" without any more details and beyond the order of time and space. Some grammatical mistakes often exist in her writing. All these features made it difficult for readers to understand her work, which also indicates the irresolvable feature of trauma.

She often gets lost even though she goes out every day. On one hand, "repeated loss" symbolizes the breaking of the connection between the individual and the surrounding environment. On the other hand, the chaos of memory also shows the effect of trauma. When this fracture is reflected in the mind, it will lead to the loss of self-consciousness.

What's worse, people must often change their careers or identities to survive. In the novel, Anna first cuts off her long hair and turns into a tomboy, then immediately turns into a social worker from a garbage collector. The frequent change of identity further aggravates the split and loss of individual awareness. Being lost is just the beginning for most people. Only in this way can they survive in the space full of violence and poverty. A typical example is Sam, another 
character in the novel. He is eager to abandon himself and everything around him, so that he almost lives like a stone and lives in a place without harm. Sam's effort to erase himself and achieve indifference is similar to defensive autism. This is a fatal paradox imposed on individuals by space: "if you want to live, you must let yourself die" [5]. Many people become hollow individuals who have lost their will and linger with the continuous demise of the subject.

\subsection{The Ubiquitous Aphasia}

In the novel, the fragmented aphasia can also be seen everywhere because of the lack of self-consciousness and language ability. First, this kind of spiritual space can easily lead to the loss of self-consciousness. As mentioned above, the visible space here is very fragile and easy to change and greatly inhibits and hinders consciousness.

There are mainly two forms of aphasia in novels: explicit aphasia and implicit aphasia. The former, like the general description of aphasia in medicine, is characterized by the loss of part or all the language ability due to the disorder of the brain language center. For example, in the novel, some people who stutter and mumble often have sudden omission, forced repetition and many grammatical errors. The latter is mainly reflected in the language of the "ghost" described in the novel. They enter the illusion and fill the loss of life with all kinds of daydreams like schizophrenics. The speakers are so detailed that the listeners are so engrossed that they even forget their hunger and enter a "state of eternal glory" [5]. For example, some of them like to name everything with carnival black humor. Some of them are interested in the topic of food, from soup and appetizers to desserts and various seasonings.

To a certain extent, explicit aphasia is used by the author to express the lack of the ability of the people at the bottom to construct a coherent self, while implicit aphasia represents the negative escapist in real life. The cruelty of real life has completely destroyed people so they either lose their normal language function or express their distorted psychology with deformed and broken language. Alternatively, they simply rely on absurd words to express the traumatic experience and meet the death in the brilliance of imagination.

In essence, no matter the type of aphasia, it is often the result of the loss of collective identities, which further reveals the double torture and severe destruction of the body and mind caused by this repressed spiritual space.

\subsection{The Others' Alienation}

Meanwhile, the city also spawned some monsters of absolute otherness. Some people are completely engulfed by anger and despair, which eventually leads to the complete alienation of personality and spirit. For example, various monsters appeared in the city. Some of them are strange in appearance and are "like some kind of monster full of malice sitting in a corner sulking" [5]. In the same vein, others are strange in behavior, wriggling with their limbs or abdomen, or run- 
ning in groups and yelling loudly until they are exhausted and fall to the ground and die. They are all small people who are suffering humiliation and torture while waiting for the destruction of their lives. They are helpless and have to endure the plight, and they use their abnormal lives to vent their inner depression and sorrow. Through their struggles, readers can clearly see the spiritual anxiety caused by the imbalance between space and power, as well as the resulting split personality and psychosis after the traumatic experience.

According to Michel Foucault's theory of power, "Discipline may be identified neither with an institution nor with an apparatus; it is a type of power, a modality for its exercise, comprising a whole set of instruments, techniques, procedures, levels of application, target; it is a 'physics' or an 'anatomy' of power, a technology" [7]. Therefore, their rebellious image represents chaos, transgression and irrationality. As a result, they have seemingly reasonable excuses for the exclusion and oppression. These vulnerable groups are facing serious obstacles in the construction of their own identities, and they also fail to speak for themselves with different language problems. As a medium of privilege, there has always been a collusive relationship between language and power. Only by using language successfully can people share meaning and power. Therefore, unobstructed language often means the hidden identification of the power [8]. Consequently, damaged language symbolizes the silent restriction or exclusion of power. The residents of the city generally suffer from aphasia, which shows that the heterogeneous space will not only hinder the construction of the subject, but also lead to the heterogeneity of the group language, until the complete loss of the right to speak.

The most typical collective aphasia in the novel can be attributed to the fact that it is difficult to remember and speak after trauma. Feldman once pointed out that trauma experience is "a different kind of human being outside the frame of reference, which is beyond the limit of human ability (and willingness) to grasp, convey or imagine" [9]. Essentially, trauma is unforgettable, let alone speechless. The vast majority of residents in the city have experienced trauma in different ways. These traumas can neither be sorted nor integrated into their own consciousness, so it is more difficult to speak or write in language, let alone to express logically and coherently. Anna wrote down in her diary that "if you find yourself looking at a dead child, a little girl lying naked on the street, her head crushed, her face covered with blood, it's hard to say it coldly, directly and coherently. Your thoughts seem to be blocked and you can't combine these words. Somehow, you just can't speak them" [5]. Her experience also illustrates the problem of expression caused by a traumatic experience. When the speaker is still in extreme confusion and pain, there is no corresponding expression between words and objects.

The city is not only in crisis, it's disintegrating. Due to the long-term isolation, most people go to the streets to pick up waste in a solitary way, and they don't communicate with each other. The memory of the city is also collapsing with the 
collapse of words and meanings. The residents who are isolated behind the private wall have no public memory to communicate with. After all, memory is not controlled by will, but an involuntary act. What this person still remembers may have been forgotten by another person forever, which creates difficulties for mutual understanding, an obstacle that cannot be joyful. As a matter of fact, everyone speaks his own language, and with less and less consensus, people's communication becomes more and more difficult. As a result, the library has become a ruin in a city of doomsday where everyone is aiming to live, who will have the spare time to read. However, writing is necessary, even if not for the present readers, but also for the future readers. Anna was in the library, burning books to keep warm and living, while writing her own books.

\section{Conclusions}

Paul Auster's work was published in 1987. It describes the city of doomsday, which is exaggerated despair, but at the same time, Auster could not predict in the 1980s, and it is also beyond the description of that imagined space-the social networks we have during the COVID-19. This invisible public space is the final place for us to place our personal emotions and public memory. However, most of the time, there's a fierce conflict between the two. As a novel, the city of doomsday brings the same truth as the Harry Potter series: never leave your friends. However, the urban atmosphere constructed by it may provide us with an opportunity to reflect on our lives in isolation. When the normality of our past life disappears and the things available to us disappear, what is the center of our lives? When we can't work, what is the real reward we should give ourselves through labor?

Although it seems indifferent to talk about this kind of personal life through Paul Auster's works at a time when people should rush to reality and give full play to their sense of social responsibility. Literature always stands with the former in another sense. If personal life is paralyzed due to the paralysis of the city and society, such a doomsday will also be despairing.

After 15 years, Paul Auster finally presents the readers with a real and cruel social dilemma in fragmentary language through postmodern writing. In the unique form of female letters, the novel records people's struggles, suffering, and precious memories. Meanwhile, the spatial levels of the novel include the multi-level relations of politics, economy, culture, identity and language. Through close reading, this thesis also further reveals the connection between social relations and power contained in the division of space, as well as the great trauma caused by disconnection of people's body and mind. At the same time, it also reflects Auster's deep thinking about the cruel social reality and his unrelenting pursuit of individual freedom and the meaning of life.

\section{Conflicts of Interest}

The author declares no conflicts of interest. 


\section{References}

[1] Bleiler, E.F. (2000) Almanacs of Urban Decay. Contemporary Literary Criticism, $131,11$.

[2] Brown, M. (2007) Paul Auster. Manchester University Press, Manchester.

[3] Auster, P. (1987) In the Country of Last Things. Viking Press, New York.

[4] 童强. 空间哲学 $[\mathrm{M}]$. 北京: 北京大学出版社, 2011.

[5] 保罗.奥斯特. 末世之城 $[\mathrm{M}]$. 韩良忆, 译. 北京: 人民文学出版社, 2011.

[6] Cathy, C. (1996) Unclaimed Experience: Trauma, Narrative, and History. The Johns Hopkins University Press, Baltimore and London, 11.

[7] Foucault, M. (1995) Discipline and Punish: The Birth of the Prison. Vintage Books, New York, 215.

[8] 福柯. 空间、知识、权力 $[\mathrm{M}] / /$ 包亚明. 后现代性与地理学的政治. 上海: 上海教 育出版社, 2001: 13-14.

[9] 陆扬. 空间理论和文学空间[J]. 外国文学研究, 2004(4): 31-37. 